\section{Potential Sources of Whitefly (Hemiptera: Aleyrodidae) Resistance in Desert Watermelon (Citrullus colocynthis) Germplasm}

\author{
John L. Coffey \\ College of Charleston Master of Science in Environmental Studies Program, \\ 66 George Street, Charleston, SC 29424; and the U.S. Department of \\ Agriculture, Agricultural Research Service, U.S. Vegetable Laboratory, \\ 2700 Savannah Highway, Charleston, SC 29414 \\ Alvin M. Simmons ${ }^{1}$ \\ U.S. Department of Agriculture, Agricultural Research Service, U.S. \\ Vegetable Laboratory, 2700 Savannah Highway, Charleston, SC 29414
}

\author{
B. Merle Shepard \\ Clemson University, Coastal Research and Education Center, \\ 2700 Savannah Highway, Charleston, SC 29414
}

Yaakov Tadmor Agricultural Research Organization, Volcani Center, Bet Dagan, Israel

\begin{abstract}
Amnon Levi
U.S. Department of Agriculture, Agricultural Research Service, U.S. Vegetable Laboratory, 2700 Savannah Highway, Charleston, SC 29414
\end{abstract}

Additional index words. Bemisia tabaci, Citrullus lanatus, breeding, germplasm, genetics, pest resistance

\begin{abstract}
Selection for and incorporation of host plant resistance into cultivars is a fundamental strategy to control insects and diseases and may help reduce reliance on synthetic pesticides. The sweetpotato whitefly, Bemisia tabaci (Gennadius), is an important pest of watermelon [Citrullus lanatus (Thunberg) Matsum. and Nakai var. lanatus] and is among the most damaging pests in many agricultural systems worldwide. Citrullus colocynthis L., a perennial melon species indigenous to arid regions of northern Africa, the Mediterranean region, and southwestern Asia, is a valuable source of resistance to insect pests and diseases of watermelon. Laboratory and greenhouse experiments were conducted to evaluate selected $C$. colocynthis genotypes for sources of resistance to $B$. tabaci. Thirty genotypes of $C$. colocynthis, collected in different geographic regions, were evaluated against the heirloom cultivar Calhoun Gray using first a horizontal Y-tube olfactometer in the laboratory. A selected subset of the genotypes was evaluated in a second experiment in the laboratory using a vertical monitoring assay. In this assay, whiteflies could freely move upward to feed and oviposit on leaves placed in the upper portion of a Y-tube. In a third experiment, a choice assay was conducted on selected genotypes in cages in the greenhouse. Of the $30 \mathrm{C}$. colocynthis genotypes evaluated, PI 346082 (collected in Afghanistan) exhibited the highest level of resistance against $B$. tabaci based on all three experiments. PI 537277 (collected in Pakistan) exhibited a significantly high level of whitefly resistance based on low survival of adult whiteflies and a low ratio of nymphs to eggs. PI 346082 and PI 537277 should be a useful source for breeding projects aiming to improve whitefly resistance in watermelon cultivars.
\end{abstract}

Watermelon cultivars [Citrullus lanatus (Thunberg) Matsum. and Nakai var. lanatus] share a narrow genetic base (Levi et al., 2001a) and are susceptible to a large number of pests and diseases including whiteflies (Hemiptera: Aleyrodidae) (Simmons and Levi, 2002). Whiteflies damage numerous crops, including watermelon, through both direct and indirect feeding (Simmons and Levi, 2002). Direct herbivory may result in deformation of leaf tissue, defoliation, and dehydration resulting from sap loss. Digestion of plant sap by whiteflies results in excretion of a viscous fluid referred to as honeydew, which may increase the incidence of fungal infection as well as sticky fruit surfaces. In addition to feeding damage, whiteflies are important vectors of numerous plant viruses (Kousik et al., 2012; Togni et al., 2010).

The sweetpotato whitefly, Bemisia tabaci (Gennadius), is particularly abundant in warm habitats (McKenzie et al., 2004) and feeds on over 1000 plant species (Abd-Rabou and Simmons, 2010; Simmons et al., 2008). The B. tabaci complex has been described as the most significant pest in many agricultural crop systems worldwide (Togni et al., 2010) and has been implicated as a vector of over 100 plant viruses (Jones, 2003; Yang et al., 2013) resulting in significant economic loss. The B-biotype is also known as Middle East-Asia Minor 1 (MEAM1) (Dinsdale et al., 2010). It is a particularly problematic pest. For example, in southwest and west-central Florida, Squash vein yellowing virus transmitted by B-biotype B. tabaci resulted in damage to the watermelon crop estimated at over U.S. \$60 million in the 2004-05 season (Kousik et al., 2012). In other crop systems, losses of up to $100 \%$ have been documented resulting from viruses transmitted by whiteflies (Togni et al., 2010).

Insecticides are the primary control strategy for managing whiteflies; however, many insecticides also kill predators and parasitoids of whiteflies (Simmons and Abd-Rabou 2005, 2011) and may negatively impact bees (Chensheng et al., 2014) and other agriculturally important pollinators (Brittain et al., 2010). $B$. tabaci has rapidly developed resistance to insecticides with resistance having been reported to over 40 active ingredients (Vassiliou et al., 2011) representing all of the major classes of synthetic insecticides (Caballero et al., 2013). Concerns in the scientific and agricultural communities regarding reliance on pesticides and the continuous emergence of new pests and diseases (Park and Cho, 2012) emphasize the importance of developing more sustainable control strategies. Host plant resistance is the most fundamental sustainable management strategy (Simmons and Levi, 2002).

General pest resistance in cultivated watermelon was apparently lost during the many years of domestication and selection for desirable traits, including increased sugar content and red flesh (Levi et al., 2001a, 2001b). Conversely, various wild desert melons in the genus Citrullus, including C. colocynthis (L.) Schrad, C. rehmii De Winter, and C. ecirrhosus Cogniaux, hold potential sources of resistance to whiteflies. Citrullus colocynthis is a perennial melon species that exists in the deserts of northern Africa, southwest and central Asia (Iran, Afghanistan, Pakistan, and India), and the Mediterranean Basin (Simmons and Levi, 2002). In addition to its tolerance to harsh environmental conditions, $C$. colocynthis is a viable source of resistance against insects and diseases of watermelon. A wide genetic distance exists between $C$. colocynthis and cultivated watermelon (Levi et al., 2002, 
2013). However, interspecific crosses are possible and the seeds generated from crosses between these Citrullus sp. are viable (Levi et al., 2013).

Olfactometer bioassays can be used to assess whitefly nonpreference for different sources of volatiles as an indirect method for identifying genotypes that exhibit natural host plant resistance (Togni et al., 2010). Olfactometer assays have demonstrated whitefly repellency by mustard, Brassica juncea L. Czern. (Legaspi et al., 2011), and ginger, Zingiber officinale (Zhang et al., 2004). Whitefly preference for tomato, Solanum lycopersicum L., was shown to be reduced when coriander, Coriandrum sativum L., volatiles were present (Togni et al., 2010). Olfactometer assays were used to elucidate a repellent effect of C. colocynthis extract on the cowpea weevil, Callosobruchus maculatus Fab. (Seenivasan et al., 2005), and the potato tuber moth, Phthorimaea operculella Zell. (Sharaby et al., 2009). There has not been any report of olfactometer assays of C. colocynthis and whiteflies. The objective of this study was to evaluate selected genotypes of $C$. colocynthis for natural host plant resistance to $B$. tabaci using choice and no-choice laboratory assays followed by a choice greenhouse assay.

\section{Materials and Methods}

Source of insects. Whiteflies used in this study were from a greenhouse colony of B-biotype $B$. tabaci that originated from a feral population collected on sweetpotato and reared on assorted uncaged vegetables (Simmons and Levi, 2002). The colony of whiteflies was not exposed to pesticides at any time. For all trials, adult whiteflies were collected from 'Georgia' collard, Brassica oleracea var. acephala (L.), by mouth aspiration from leaf surfaces into $30-\mathrm{mL}$ plastic vials. The whiteflies were starved for $2 \mathrm{~h}$ before each olfactometer experiment, but there was no starvation before the greenhouse experiment.

Plant material. Thirty C. colocynthis genotypes and the cultivated watermelon 'Calhoun Gray' were included in this study (Table 1). Seeds for 21 C. colocynthis PI accessions were obtained from the USDA, ARS, Plant Genetic Resources Conservation Unit at Griffin, GA; the unit maintains 24 PIs classified as $C$. colocynthis. Seeds for nine additional genotypes of $C$. colocynthis, which lacked screening for pest resistance and were collected in Israel, were obtained from the Agricultural Research Organization, Israel Gene Bank. 'Calhoun Gray' seeds were obtained from Sunseeds (Sunseeds Company, Acampo, CA). Plants were grown from seed in a potting mixture consisting of $35 \%$ to $45 \%$ Canadian sphagnum peatmoss, vermiculite, composted bark, bark ash, dolomite lime, and gypsum (MetroMix 360; Sungro Horticulture, Seba Beach, Alberta, Canada) amended with $\approx 10 \%$ sand by volume. At least four plants for each genotype were grown in a common greenhouse. No pesticide was applied to any of the plants at any time. In all trials, the third leaf below the apical meristem was selected.
Standard olfactometer choice bioassay. A Y-tube olfactometer (Prism Research Glass, Raleigh, NC) was used, which consisted of two separate glass compartments $(13 \mathrm{~cm}$ diameter $\times 20 \mathrm{~cm}$ height, approximate volume $2650 \mathrm{~cm}^{3}$ ) connected to separate glass arms of the Y-tube with silicone tubing. The olfactometer was connected through $65 \mathrm{~cm}$ of silicon tubing to a vacuum line that was calibrated (Graftel LLC, Oak Grove Village, IL) to generate a total flow of $4.2 \mathrm{~L} \cdot \mathrm{min}^{-1}$. Air was pulled across the leaf surfaces of the samples in the glass compartments, presenting the whitefly with a stream of leaf volatiles. The whitefly had a choice to move toward either sample through one of the arms of the Y-tube or the whitefly could remain near the entrance of the Y-tube with no movement toward either sample. The base of the Y-tube was $8 \mathrm{~cm}$ long and each arm of the Y-tube was $6 \mathrm{~cm}$ long. For each assay, a single adult whitefly was manually aspirated into a glass pipette and released into the entrance of the base of the Y-tube by a gentle tap of a pipet. Moving $2 \mathrm{~cm}$ or greater into an arm for $10 \mathrm{~s}$ or longer was designated as a choice. If the whitefly failed to move $2 \mathrm{~cm}$ or greater into either arm of the Y-tube after 5 min, a "no choice" result was documented. Each whitefly was assayed only once. A preliminary control experiment was conducted to elucidate any environmental influences or cofounding variables that may influence whitefly preference for one compartment over the other as well as to assess the validity of the experimental design for detecting whitefly non-preference between genotypes. Control trials consisted of evaluating whitefly choice when both compartments were left empty as well as when one compartment contained 'Calhoun Gray' and the other compartment was left empty. Sixty trials, one whitefly each, were done for the control experiment.

For the choice assay, each $C$. colocynthis accession was evaluated vs. the 'Calhoun Gray' cultivar in a randomized design. A total of 10 adult whiteflies per $C$. colocynthis accession was assayed. Evaluation of plant material was randomized. Placement of the leaves, position of the compartments, and orientation of Y-tube of the olfactometer were rotated after every five whiteflies to avoid bias. Percentages for whitefly choice were calculated based on every five whiteflies. Based on those data (Fig. 1), seven genotypes for which whitefly mean choice was $10 \%$ or less were further evaluated. For each of these seven genotypes, a total of six replications were conducted for a total of 30 whiteflies assayed per genotype.

Vertical Y-tube no choice bioassay. A novel vertical Y-tube monitoring assay was designed and constructed (unpublished report) to improve on the traditional horizontal Y-tube olfactometer assay in terms of sensitivity in measuring whitefly non-preference as well as in affording the collection of data on antibiosis parameters that are unsuitable for measurement using the standard olfactometer. Control trials with empty compartments or with 'Calhoun Gray' as described in the standard olfactometer assay were conducted
Table 1. Collection information for 21 C. colocynthis PIs from USDA, ARS, Plant Genetic Resources Conservation Unit, Griffin, GA, and nine additional genotypes of $C$. colocynthis from the Agricultural Research Organization, Israel Gene Bank.

\begin{tabular}{ll}
\hline C. colocynthis accession & \multicolumn{1}{c}{ Country of origin } \\
\hline Grif 14201 & Rajasthan, India \\
PI 195927 & Harage, Ethiopia \\
PI 220778 & Farah, Afghanistan \\
PI 346082 & Helmand, Afghanistan \\
PI 374216 & Afghanistan \\
PI 386014 & Iran \\
PI 386015 & Iran \\
PI 386018 & Iran \\
PI 386019 & Iran \\
PI 386021 & Iran \\
PI 386024 & Iran \\
PI 386026 & Iran \\
PI 388770 & Morocco \\
PI 432337 & Cyprus \\
PI 525080 & Qena, Egypt \\
PI 525082 & Egypt \\
PI 537277 & Punjab, Pakistan \\
PI 537300 & Ahal, Turkmenistan \\
PI 542616 & Algeria \\
PI 549161 & Chad \\
PI 652554 & Rajasthan, India \\
ARO 13247 & Jordan \\
ARO 18917 & Negev Desert, Israel \\
ARO 18920 & Negev Desert, Israel \\
ARO 20587 & Negev Desert, Israel \\
ARO 21031 & Negev Desert, Israel \\
ARO 22357 & Negev Desert, Israel \\
ARO 22359 & Negev Desert, Israel \\
ARO 23701 & Negev Desert, Israel \\
ARO 23967 & Negev Desert, Israel \\
\hline &
\end{tabular}

to elucidate any environmental influences. Six replications of 30 whiteflies each were conducted for the control trials.

A no choice assay was then conducted for two selected $C$. colocynthis genotypes that appeared to exhibit the most whitefly resistance based on non-preference in the standard olfactometer assay. The 'Calhoun Gray' control and a genotype that appeared to be one of the most highly susceptible in the standard olfactometer assay were included in this assay. Five to eight replications of 30 whiteflies each were conducted for each of four entries (ARO 18917, PI 346082, PI 537277, and 'Calhoun Gray') in a randomized design $(\mathrm{n}=720)$. For each trial, the vertical Y-tube was left undisturbed for $24 \mathrm{~h}$, in the laboratory, at $25 \pm 2{ }^{\circ} \mathrm{C}$. After $24 \mathrm{~h}$, the number of live adult whiteflies on the leaf surface and the number of dead whiteflies found at the end of each trial were recorded and percent mortality calculated. Leaf samples were thoroughly examined under a binocular microscope (Leica EZ4D, Buffalo Grove, IL) and whitefly eggs were counted.

Cage choice bioassay. Ten plants of each ARO 18917, PI 346082, PI 537277, and 'Calhoun Gray' were grown from seed and individually transplanted from seedling trays into small plastic pots (volume $\approx 2300 \mathrm{~cm}^{3}$ ) 2 weeks before initiation of a cage bioassay. The cages (Bug-Dorm; BioQuip Products, Rancho Dominguez, CA) consisted of clear vinyl and white polyester netting supported by four $55-\mathrm{cm}$ long fiberglass poles. Care was taken to ensure that all plants were free from 


\section{" \% Choosing C. colocynthis $\quad$ \% Choosing 'Calhoun Gray' Cultivar}

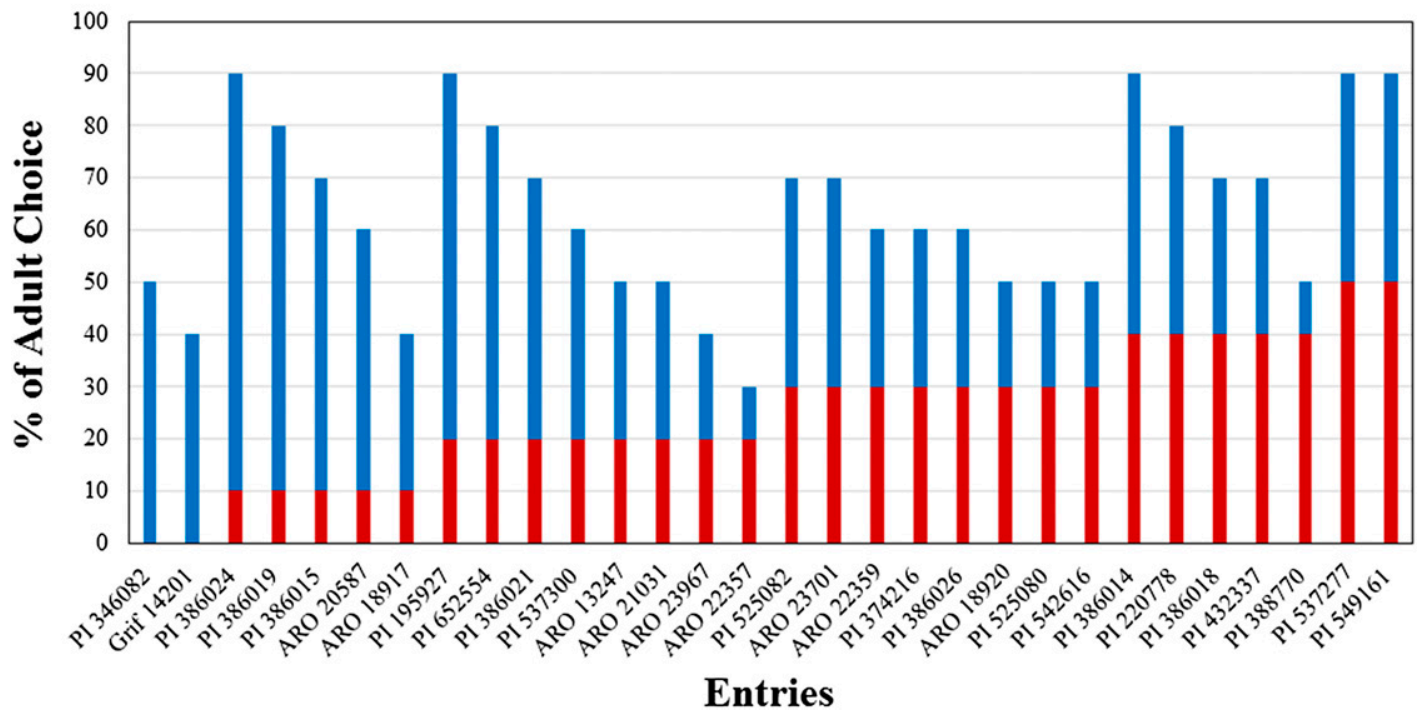

Fig. 1. Dual-choice of B. tabaci olfactometer assay between 'Calhoun Gray' watermelon and each of 30 C. colocynthis genotypes in the laboratory ( $\mathrm{n}=300$ ).

any pests or pathogens and were of similar size and number of leaves (approximately fourth true-leaf stage). Immediately before placement in the cages, each plant received $100 \mathrm{~mL}$ of tap water. Each cage contained four plants, one of each of the mentioned genotypes. Placement of the plants within each cage and location of the cages in a greenhouse were randomized. A vial containing 30 adult $B$. tabaci was introduced into the center of each cage and uncapped to allow the whiteflies to disperse. The experiment was left undisturbed for $14 \mathrm{~d}$. Water or other inputs were not introduced into the system during the experiment. On Day 15, the number of adults on the leaves was counted in situ without disturbing the plant in each cage. Each leaf was then carefully removed and examined under a microscope. The numbers of whitefly eggs and nymphs were recorded for each leaf. The area of each leaf was determined using a leaf area meter (Model LI-3000A; LI-COR, Lincoln, NE).

Statistical analyses. All statistical analyses were performed using the MiniTab Statistical Package (MiniTab Version 16, 2010, and Version 17, 2014, State College, PA). Paired $t$ tests were used to compare any differences in mean whitefly preference between treatments in the standard olfactometer choice assay. One-factor analysis of variance was used to compare means for adult counts, egg counts, nymphal counts, and percentage mortality between the different $C$. colocynthis genotypes within the vertical no choice assay and the open-choice cage assay. Tukey's $95 \%$ simultaneous confidence intervals were used to separate means by genotype for all parameters measured in the vertical no choice experiment. For the greenhouse assay, Tukey's 95\% simultaneous confidence intervals were used to separate means for adult presence and Fisher's 95\% individual confidence intervals were used to separate means for ratio of nymphs to eggs. All percentage data were transformed using arcsine transformation before analysis.

\section{Results}

Standard olfactometer control trials. When presented with two empty compartments of the standard olfactometer, $70 \%$ of the adult whiteflies exhibited no choice. There was no significant difference $(t=-0.14, \mathrm{df}=10$, $P=0.89)$ in the number of whiteflies moving to the right $(16.7 \%)$ or left $(13.3 \%)$ empty compartments. Hence, no environmental influence between compartments was detected on whitefly behavior. In an assay involving a choice between cultivar Calhoun Gray and an empty control compartment, significantly more $(37 \%, t=2.94$, df $=10, P=0.015)$ chose the compartment containing 'Calhoun Gray' as compared with the blank control $(13 \%)$, whereas $50 \%$ of the whiteflies exhibited no choice.

Standard olfactometer choice assay. In the trial involving $30 \mathrm{C}$. colocynthis genotypes and 300 adult whiteflies in a standard olfactometer choice assay (Fig. 1), whiteflies were significantly $(t=5.44, \mathrm{df}=202, P<0.0001)$ less likely to choose $C$. colocynthis genotypes ( $25 \%$ of whiteflies chose $C$. colocynthis) as compared with 'Calhoun Gray' (38\%). Seven C. colocynthis genotypes (Grif 14201, PI 346082, PI 386015, PI 386019, PI 386024, ARO 18917, and ARO 20587) were selected after they exhibited $10 \%$ or less of the whiteflies in the assay (Fig. 1). Whiteflies exhibited non-preference for the genotypes Grif 14201 and PI 346082 with no whiteflies choosing these genotypes in the first trial, whereas preference was highest for PI 537277 and PI 549161 at 50\% (Fig. 1). Each of these seven genotypes was further evaluated with 20 additional whiteflies per genotype (Table 2). Overall, whiteflies were significantly $(t=5.63, \mathrm{df}=82, P<0.0001)$ less likely to choose these seven $C$. colocynthis genotypes (17\%) compared with 'Calhoun Gray' (43\%). PI 346082 was significantly $(t=6.02, \mathrm{df}=10, P<0.001)$ more antixenotic to B. tabaci, based on this assay, as compared with the other genotypes evaluated (Table 2).

Vertical arena control trials. In the control trial involving a choice between two empty compartments, whitefly non-preference was statistically the same $(t=0.90, \mathrm{df}=10, P=0.464)$ for those selecting the left $(44 \%)$ and right (37\%) compartments. Thus, no environmental effect on their choice was detected. In the control trial involving a choice between cultivar Calhoun Gray and a blank compartment, significantly more $(t=8.29, \mathrm{df}=10, P<0.001)$ whiteflies choose 'Calhoun Gray' (84\%) as compared with the blank control $(6.6 \%)$.

Vertical no choice assay. In the no choice assay, PI 537277 harbored the fewest number of adults, exhibited the lowest oviposition rate, and had the highest mortality rate (Table 3 ). Conversely, 'Calhoun Gray' harbored the most adults and exhibited the highest oviposition rate and the lowest mortality rate (Table 3). Overall, mean adult count was significantly lower $(\mathrm{F}=15, \mathrm{df}=3,7 ; P<$ 0.001 ) for $C$. colocynthis genotypes than for 'Calhoun Gray'. Mean adult count was lowest for PI 537277 (38\%) and PI 346082 (39\%) and highest for 'Calhoun Gray' (74\%). Mean oviposition rate was significantly $(\mathrm{F}=$ 11.15 , df $=3,7 ; P<0.001)$ lower for the C. colocynthis genotypes than for 'Calhoun Gray.' Mean oviposition rate was least for PI 537277 (35.4 eggs) and PI 346082 (44.8 eggs) and highest for 'Calhoun Gray' (90.50 eggs). Mean whitefly mortality was significantly higher $(\mathrm{F}=8.81, \mathrm{df}=3,7 ; P<0.001)$ for $C$. colocynthis genotypes than for ' $\mathrm{Cal}$ houn Gray.' Mortality was highest for PI 537277 (37\%) and PI 346082 (35\%) and lowest for 'Calhoun Gray' (13\%).

Greenhouse cage assay. In the bioassay involving whiteflies placed in cages with intact plants, PI 346082 harbored the lowest density of adults, nymphs, and eggs, whereas 'Calhoun Gray' harbored the highest density of adults, nymphs, and eggs (Table 4). PI 346082 and PI 18917 harbored significantly 
Table 2. Mean percentage of released adult $B$. tabaci moving toward selected $C$. colocynthis genotypes vs. commercial cultivar Calhoun Gray watermelon in a choice assay using a standard dual-choice Ytube horizontal olfactometer in the laboratory $(n=210)$.

\begin{tabular}{lcccr}
\hline & \multicolumn{2}{c}{ Mean percent whitefly choice $\pm \mathrm{sE}^{\mathrm{z}}$} & & \\
\cline { 2 - 5 } C. colocynthis entries & C. colocynthis & 'Calhoun Gray' & $t$ & $P$ \\
\hline Grif 14201 & $16.7 \pm 6.2$ & $40.0 \pm 7.3$ & 2.44 & 0.003 \\
PI 346082 & $10.0 \pm 4.5$ & $53.3 \pm 9.9$ & 6.02 & 0.001 \\
PI 386015 & $20.0 \pm 5.2$ & $46.7 \pm 6.7$ & 2.39 & 0.031 \\
PI 386019 & $23.3 \pm 6.1$ & $40.0 \pm 10.3$ & 1.16 & 0.150 \\
PI 386024 & $20.0 \pm 5.2$ & $46.7 \pm 11.2$ & 1.76 & 0.069 \\
ARO 18917 & $16.7 \pm 8.0$ & $36.7 \pm 8.0$ & 2.66 & 0.022 \\
ARO 20587 & $13.3 \pm 4.2$ & $40.0 \pm 14.6$ & 1.28 & 0.130 \\
\hline
\end{tabular}

${ }^{\mathrm{z} C}$. colocynthis choice + 'Calhoun Gray' choice + "no choice" (not shown) $=100 \%$.

Table 3. Incidence of adults, egg deposition, and adult mortality of B. tabaci on Citrullus germplasm in $24 \mathrm{~h}$ no choice vertical monitoring assay (five to eight trials of 30 whiteflies per entry).

\begin{tabular}{lccc}
\hline Entry & $\begin{array}{c}\text { Mean percent of released } \\
\text { adults on leaf } \pm \mathrm{SE}^{\mathrm{z}}\end{array}$ & $\begin{array}{c}\text { Mean no. eggs on } \\
\text { leaf } \pm \mathrm{SE}^{\mathrm{z}}\end{array}$ & $\begin{array}{c}\text { Mean percent mortality } \\
\text { of released adults } \pm \mathrm{SE}^{\mathrm{z}}\end{array}$ \\
\hline 'Calhoun Gray' & $74.17 \pm 3.78 \mathrm{a}$ & $90.50 \pm 8.20 \mathrm{a}$ & $12.92 \pm 0.02 \mathrm{a}$ \\
ARO 18917 & $56.11 \pm 5.12 \mathrm{~b}$ & $51.17 \pm 5.42 \mathrm{~b}$ & $28.33 \pm 0.04 \mathrm{a}$ \\
PI 346082 & $38.89 \pm 6.01 \mathrm{c}$ & $44.80 \pm 6.58 \mathrm{~b}$ & $34.67 \pm 0.07 \mathrm{~b}$ \\
PI 537277 & $37.78 \pm 3.41 \mathrm{c}$ & $35.40 \pm 9.24 \mathrm{~b}$ & $37.33 \pm 0.24 \mathrm{~b}$ \\
\hline
\end{tabular}

${ }^{\mathrm{z}}$ Means in a column that do not share a letter are significantly different $(P<0.05)$ according to Tukey's test.

Table 4. Mean number of adults, eggs, and nymphs by leaf area and ratio of nymphs to eggs of $B$. tabaci on Citrullus germplasm in a 14-d choice greenhouse assay (a total of 30 adults released per cage).

\begin{tabular}{llcrr}
\hline Entry & $\begin{array}{c}\text { Number of } \\
\text { adults } / \mathrm{cm}^{2} \pm \mathrm{SE}^{\mathrm{z}}\end{array}$ & $\begin{array}{c}\text { Number of } \\
\text { no. eggs/cm } \pm \mathrm{SE}^{\mathrm{z}}\end{array}$ & $\begin{array}{c}\text { Number of } \\
\text { nymphs/cm } \pm \mathrm{sE}^{\mathrm{z}}\end{array}$ & $\begin{array}{c}\text { Ratio of nymphs } \\
\text { to eggs } \pm \mathrm{SE}^{\mathrm{y}}\end{array}$ \\
\hline 'Calhoun Gray' & $0.161 \pm 0.006 \mathrm{a}$ & $6.99 \pm 1.59 \mathrm{a}$ & $2.55 \pm 0.61 \mathrm{a}$ & $0.372 \pm 0.044 \mathrm{a}$ \\
ARO 18917 & $0.063 \pm 0.029 \mathrm{bc}$ & $6.33 \pm 3.68 \mathrm{a}$ & $2.41 \pm 1.20 \mathrm{a}$ & $0.426 \pm 0.065 \mathrm{a}$ \\
PI 346082 & $0.032 \pm 0.002 \mathrm{c}$ & $1.03 \pm 0.31 \mathrm{a}$ & $0.36 \pm 0.07 \mathrm{a}$ & $0.382 \pm 0.091 \mathrm{a}$ \\
PI 537277 & $0.128 \pm 0.016 \mathrm{ab}$ & $6.03 \pm 2.12 \mathrm{a}$ & $0.69 \pm 0.69 \mathrm{a}$ & $0.085 \pm 0.085 \mathrm{~b}$ \\
\hline
\end{tabular}

${ }^{\mathrm{z}}$ Means in a column that do not share a letter are significantly different $(P<0.05)$ according to Tukey's test. ${ }^{\mathrm{y}}$ Means in a column for ratio of nymphs to eggs that do not share a letter are significantly different $(P<$ $0.05)$ according to Fisher's test.

$(\mathrm{F}=10.92, \mathrm{df}=3,20 ; P<0.01)$ fewer adults than the other genotypes evaluated. Incidence of adults as a percentage of the population was lowest for PI 346082 (14.8\%) and PI 537277 (18.1\%), whereas 'Calhoun Gray' harbored a significantly $(\mathrm{F}=6.94$, df $=3$, $20 ; P<0.05)$ higher percentage $(50.5 \%)$ of adults than the other genotypes evaluated. Mean number of eggs was lowest for PI 346082 (187.7 eggs/plant) and PI 537277 (212.0 eggs/plant) and highest for 'Calhoun Gray' (498.3 eggs/plant). Mean number of nymphs was lowest for PI $537277(24.0$ nymphs/plant) and PI 346082 (58.3 nymphs/plant) and highest for 'Calhoun Gray' (194.7 nymphs/plant). The ratio of nymphs to eggs was lowest $(0.085)$ for PI 537277. Adult density, total number of adults, and mean count of adults as a percentage of the population were highest for 'Calhoun Gray' in every cage.

\section{Discussion}

This study is the first report on the use of olfactometer assays to examine whitefly antixenosis in C. colocynthis genotypes. Based on observations of 1520 adult whiteflies included in this study as well as immatures and eggs, PI 346082 (collected in Afghanistan) exhibited the highest level of resistance against $B$. tabaci in both laboratory and greenhouse experiments. PI 537277 (collected in Pakistan) exhibited a high level of whitefly resistance based on low whitefly survival in the laboratory as well as a very low ratio of nymphs to eggs in the open-choice greenhouse experiment. Simmons and Levi (2002) evaluated Citrullus germplasm for resistance to whiteflies using choice, no choice, and survival bioassays. Their study included seven watermelon cultivars, a triploid line, 16 PIs of C. lanatus var. lanatus, 10 PIs of C. lanatus var. citroides, and eight PIs of C. colocynthis. However, there had not been any previous reports on evaluating a large number of $C$. colocynthis PIs collected from around the world. The precise mechanisms contributing to the observed resistance to whitefly in $C$. colocynthis genotypes have yet to be fully elucidated. We recently reported on some differences in leaf chemical profiles between some C. colocynthis and some watermelon cultivars, but the role of the chemicals for whitefly resistance was not may be mediated by several factors including non-preference and the ability of a plant to repel or otherwise defend against the development of insect pest infestation such as was observed in PI 346082. Resistance may also be mediated by antibiosis, the ability of a plant to reduce the fitness of the insect pest through the production of compounds that are adverse to the insect pest, or indirectly through production of compounds that attract natural enemies of the insect pest. In the laboratory no choice bioassay, PI 537277 was associated with the highest whitefly mortality rate (38\%). Moreover, although PI 537277 ascertained (Ogbuji et al., 2012). Resistance was comparable to 'Calhoun Gray' regarding adult counts and oviposition, the ratio of nymphs to eggs for PI 537277 was an order of magnitude lower than any of the other genotypes evaluated in the greenhouse assay. In concert with the high mortality rate in the laboratory, because PI 537277 harbored many eggs but almost no nymphs in the greenhouse, this suggests an antibiosis effect by this genotype on $B$. tabaci. Resistance may also be mediated through the ability of a plant to tolerate the impact of the insect pest feeding, i.e., a plant continues to thrive despite infestation by a pest. Observable differences were noticed in the appearance of the plants in the whitefly cages; most C. colocynthis plants were healthy with new growth, whereas most 'Calhoun Gray' plants were stunted or died shortly after the end of the experiment.

Natural host plant resistance to insects and diseases is a management strategy that may help reduce the use of synthetic pesticides and mitigate negative effects on non-target organisms including natural enemies of pests and important pollinators. The identification of genotypes that exhibit resistance to multiple pests or pathogens and the identification of multiple mechanisms of resistance are of particular importance in the development of elite cultivars exhibiting broad resistance to many insects and diseases. This is the first report on the use of olfactometer bioassays to examine whitefly antixenosis in watermelon ( $C$. lanatus var. lanatus) vs. $C$. colocynthis genotypes. Although this study concerns Citrullus species and whiteflies, the approach of identifying natural resistance in closely related wild, feral, and landrace germplasm, and incorporating this resistance into commercial cultivars, may be applicable to numerous crops. This may contribute to the global objective of increasing sustainability and reducing the use of synthetic pesticides in diverse agroecosystems.

\section{Literature Cited}

Abd-Rabou, S. and A.M. Simmons. 2010. Survey of reproductive host plants of Bemisia tabaci (Hemiptera: Aleyrodidae) in Egypt, including new host records. Entomol. News 121:456465.

Brittain, C.A., M. Vighi, R. Bommarco, J. Settele, and S.G. Potts. 2010. Impacts of a pesticide on pollinator species richness at different spatial scales. Basic App. Ecol. 2:106-115.

Caballero, R., S. Cyman, and D. Schuster. 2013. Monitoring insecticide resistance in Biotype B of Bemisia tabaci (Hempitera: Aleyrodidae) in Florida. Fla. Entomol. 96:1243-1256.

Chensheng, L., K.M. Warchol, and R.A. Callahan. 2014. Sub-lethal exposure to neonicotinoids impaired honey bees winterization before proceeding to colony collapse disorder. Bull. Insectology 67:125-130.

Dinsdale, A., L. Cook, C. Riginos, Y.M. Buckley, and P. DeBarro. 2010. Refined global analysis of Bemisia tabaci (Hemiptera: Sternorrhyncha: Aleyrodoidea: Aleyrodidae) mitochondrial cytochrome oxidase 1 to identify species level genetic boundaries. Ann. Entomol. Soc. Am. 103:196-208. 
Jones, D. 2003. Plant viruses transmitted by whiteflies. Eur. J. Plant Pathol. 109:195-219.

Kousik, C., S. Adkins, W.W. Turechek, C.G. Webster, S.E. Webb, C.A. Baker, P.A. Stansly, and P.D. Roberts. 2012. Progress and Challenges in managing watermelon vine decline cause by whitefly-transmitted Squash vein yellowing virus (SqVYV). Isr. J. Plant Sci. 60:435-445.

Legaspi, J.C., A.M. Simmons, and B.C. Legaspi. 2011. Evaluating mustard as a potential companion crop for collards to control the silverleaf whitefly, Bemisia argentifolii (Hemiptera: Aleyrodidae): Olfactometer and outdoor experiments. Subtrop. Plant Sci. 63:36-44.

Levi, A., J.A. Thies, W.P. Wechter, H.F. Harrison, A.M. Simmons, U.K. Reddy, P. Nimmakayala, and Z. Fei. 2013. High frequency oligonucleotides: Targeting active gene (HFO-TAG) markers revealed wide genetic diversity among Citrullus spp. accessions useful for enhancing disease or pest resistance in watermelon cultivars. Genet. Resources Crop Evol. 60:427440.

Levi, A., C.E. Thomas, T. Joobeur, X. Zhang, and A. Davis. 2002. A genetic linkage map for watermelon derived from a testcross population: (Citrullus lanatus var. citroides $\times$ C. lanatus var. lanatus $) \times$ Citrullus colocynthis. Theor. Appl. Genet. 105:555-563.

Levi, A., C.E. Thomas, T.C. Wehner, and X.P. Zhang. 2001a. Low genetic diversity indicates the need to broaden the genetic base of cultivated watermelon. HortScience 6:1096-1101.
Levi, A., C.E. Thomas, A.P. Keinath, and T.C. Wehner. 2001b. Genetic diversity among watermelon (Citrullus lanatus and Citrullus colocynthis) accessions. Genet. Resources Crop Evol. 48:559-566.

McKenzie, C.L., P.K. Anderson, and N. Villarreal. 2004. An extensive survey of Bemisia tabaci (Homoptera: Aleyrodidae) in agricultural ecosystems in Florida. Fla. Entomol. 87:403-407.

Ogbuji, K., G.S. McCutcheon, A.M. Simmons, M.E. Snook, H.F. Harrison, and A. Levi. 2012. Partial leaf martinchemical profiles of a desert watermelon species (Citrullus colocynthis) and heirloom watermelon cultivars (Citrullus lanatus var. lanatus). HortScience 47:580-584.

Park, Y. and S. Cho. 2012. Watermelon production and breeding in South Korea. Isr. J. Plant Sci. 60:415-423.

Seenivasan, S., M. Jayakumar, N. Raja, and S. Ignacimuthu. 2005. Evaluation of bitter apple (Citrullus colocynthis) fruit extracts against pulse beetle, Callosobruchus maculatus Fab. (Coleoptera: Bruchidae), p. 241-250. In: Ignacimuthu, S. and S. Jayaraj (eds.). Green pesticides for insect pest management. Narosa Publishing House, New Delhi, India.

Sharaby, A., H. Abdel-Rahman, and S. Moawad. 2009. Biological effects of some natural and chemical compounds on the potato tuber moth, Phthorimaea operculella Zell. (Lepidoptera: Gelechiidae). Saudi J. Biol. Sci. 16:1-9.

Simmons, A.M. and S. Abd-Rabou. 2005. Incidence of parasitism of Bemisia tabaci (Homoptera: Aleyrodidae) in three vegetable crops after application of biorational insecticides. J. Entomol. Sci. 40:474-477.

Simmons, A.M. and S. Abd-Rabou. 2011. Populations of predators and parasitoids of Bemisia tabaci (Hemiptera: Aleyrodidae) after the application of eight biorational insecticides in vegetable crops. Pest Mgt. Sci. 67:1023-1028.

Simmons, A.M., H.F. Harrison, and K. Ling. 2008 Forty-nine new host plant species for Bemisia tabaci (Hemiptera: Aleyrodidae). Entomol. Sci. 11:385-390.

Simmons, A.M. and A. Levi. 2002. Sources of whitefly (Homoptera: Aleyrodidae) resistance in Citrullus for the improvement of cultivated watermelon. HortScience 3:581-584.

Togni, P., R.A. Laumann, M.A. Medeiros, and E.R. Sujii. 2010. Odour masking of tomato volatiles by coriander volatiles in host plant selection of Bemisia tabaci biotype B. Entomol. Exp. Appl. 136:164-173.

Vassiliou, V., M. Emmanouilidou, A. Perrakis, E. Morou, J. Vontas, A. Tsagkarakou, and E. Roditakis. 2011. Insecticide resistance in Bemisia tabaci from Cyprus. Insect Sci. 18:30-39.

Yang, X., X. Wen, S. Wang, Q. Wu, H. Pan, R. Li, N. Yang, B. Liu, B. Xu, X. Zhou, and Y. Zhang. 2013. Two cytochrome $P 450$ genes are involved in imidacloprid resistance in field populations of the whitefly, Bemisia tabaci, in China. Pestic. Biochem. Physiol. 107:343-350.

Zhang, W., H.J. McAuslane, and D.J. Schuster. 2004. Repellency of ginger oil to Bemisia argentifolii (Homoptera: Aleyrodidae) on tomato. J. Econ. Entomol. 97:1310-1318. 